\title{
Numerical and Experimental Studies of Compression-Tested Copper: Proposal for a New Friction Correction
}

\author{
Gabriel Torrente $^{a * 10}$ \\ ${ }^{a}$ Departamento de Mecánica, Universidad Simón Bolívar, Valle de Sartenejas, Apartado 89000, \\ Caracas, Venezuela
}

Received: October 03, 2017; Revised: March 13, 2018; Accepted: April 04, 2018

\begin{abstract}
New empirical relationship is proposed to calculate instantaneous maximum diameters on the sample during compression test. The proposal is a relationship between instantaneous maximum diameter, friction coefficient, initial dimensions of the sample and the displacement during the compression test. Seventeen compression tests were carried out to copper cylindrical samples without lubrication at room temperature to obtain this new empirical relationship. Numerical simulations were carried out taking into a count this new relationship for numerical validation. The maximum diameters calculated with this new empirical relationship are the same to the experimental measurements. The mechanical behavior calculated with this new relationship and with the friction corrections of Rowe and Dieter are similar. The simulations are similar to the experiments, with differences lower than $4.21 \%$. The simulation shows higher hardening in the middle of the sample than on the bottom. Numerical simulations show that, possibly, the friction coefficient between sample and dies changes meanwhile the sample is hardening.
\end{abstract}

Keywords: Compression test, Barreling, Friction Correction, Copper.

\section{Introduction}

Compression test provides useful information to estimate power requirements and other characteristics of the manufacturing processes, especially for processes such as forging, rolling and extrusion. ${ }^{1}$

Compression test is usually carried out by compressing a cylindrical sample between two flat dies. The friction between dies and sample avoids the free expansion of surfaces, causing the barreling of the sample. ${ }^{1}$

Barreling is the change of the cross-sectional area in the samples with the height during the compression tests, which makes it difficult to obtain the curves of Stress vs. Strain. Additionally, the friction dissipates energy, so the compression force is greater than it would be. ${ }^{1}$

Two friction corrections have been widely accepted ${ }^{2}$; the friction correction proposed by Rowe ${ }^{3}$ and the friction correction proposed by Dieter ${ }^{4}$. These friction corrections can be written as the equations 1 and 2, respectively:

$$
\begin{gathered}
\sigma=\frac{\sigma_{Z}}{\left(1+\frac{2 f r_{i}}{3 \sqrt{3 h_{i}}}\right)} \\
\sigma=\frac{C_{f}^{2} \sigma_{Z}}{2\left[\exp \left(C_{f}\right)-C_{f}-1\right]}
\end{gathered}
$$

$r_{i}$ is the instantaneous radius, $\sigma$ and $\sigma_{z}$ are the axial stresses without and with friction, respectively; $f$ is the Tresca Friction Coefficient and can be written as $f=\sqrt{3} \mu, C_{f}$ is the Coulomb stress distribution and can be written as $C_{f}=2 \mu r / h$. These equations are for cylindrical sample and they assume that the barreling is negligible. ${ }^{2}$

Ettouney et al..$^{5}$ in 1983 used the Bridgman correction factor ${ }^{6}$ for compression tests of aluminum alloys. They determined an approximate solution for cylindrical samples with presence of barreling. They proposed that the effective stress, $\sigma$ can be writer by equation 3 :

$$
\sigma=\left(\sigma_{Z}\right)_{\text {ave }}\left\{\left[1-\frac{2 R}{D_{m}}\right] \ln \left[1-\frac{D_{m}}{2 R}\right]\right\}^{-1}
$$

And

$$
\left(\sigma_{Z}\right)_{a v e}=\frac{4 L}{\pi D_{m}^{2}}
$$

$L$ is the compression load and $R$ the bulge radius. They calculated the bulged radius using the equation proposed by Kulkarni and Kalpakgian ${ }^{7}$, where $R$ can be written by equation 5 .

$$
R=\frac{H^{2}+\left(D_{m}-D_{e}\right)^{2}}{4\left(D_{m}-D_{e}\right)}
$$

$D_{e}, D_{m}$ and $H$ are the bottom diameter, the maximum diameter the height of the sample.

Ebrahimi et al. ${ }^{8}$ in 2004 proposed a new friction correction for hot compression tests carried out to cylindrical samples of Ti-IF-steel. They proposal an average friction coefficient like a function of dimensions of the deformed samples, see equation 6 and 7. 


$$
\mu_{a v g}=\frac{\left(\frac{R_{c c p}}{H}\right) b}{\left(\frac{4}{\sqrt{3}}\right)-\frac{2 b}{3 \sqrt{3}}}
$$

And

$$
b=4 \frac{\Delta R}{R_{v c p}} \frac{H}{\Delta H}
$$

$\Delta R$ is the difference between the maximum and bottom radius $\left(R_{m}-R_{e}\right)$, the theoretic radius $\mathrm{R}_{\mathrm{vcp}}$ is calculated with the volume conservation principle, being $R_{0}, H_{0}$ the initial radius and initial height, respectively, and $H$ is the actual height

$$
R_{\mathrm{vcp}}=R_{0} \sqrt{\frac{H_{0}}{H}}
$$

The equations 7 and 8 and experimental measurements of the radius $\left(R_{m}\right.$ and $\left.R_{e}\right)$ are needed to calculate the average friction factor.

Ebrahimi et $a l .{ }^{8}$ proposed an equation to calculate the radius on the bottom. See equation 9 .

$$
R_{e}=\sqrt{3 \frac{H_{0}}{H} R_{0}^{2}}-2 R_{m}^{2}
$$

Li et al. ${ }^{9}$ in 2009 studied the hot compression tests carried out to cylindrical samples of IHS38MSV steel. They proposed for hot compression test a non-constant friction coefficient $\mu_{\mathrm{s}}$, and a way to find it, see equation 10 .

$$
\mu_{s}=\mu_{0}-A \exp \left(\varepsilon / \varepsilon_{0}\right)
$$

$\mu_{0}$, A, and $\varepsilon_{0}$ are constants values calculated experimentally.

Joardar et al. ${ }^{10}$ in 2013 presented a manuscript about compression tests carried out to cylindrical samples of composite (LM6/SiCp). They found a linear relationship between the logarithm of instantaneous maximum diameter and the logarithm of instantaneous height and proposed a relationship between the bulge radius, $R$, and the stress:

$$
R=A \sigma^{-m}
$$

$\sigma$ is the true axial stress, A and $m$ are empirical constants.

Altinbalik et al. ${ }^{11}$ in 2011 studied the compression tests carried out to cylindrical samples of AA6082. They proposed a simple empirical expression to find the stress, see equation 12 .

$$
\sigma=\frac{8 L}{\pi\left(\frac{3 H_{0} D_{0}^{2}}{H}-D_{m}^{2}\right)}
$$

$\sigma$ is the compressive stress, $L$ is the load, $H_{0}$ and $D_{0}$ are the initial height and the initial diameter of the sample, $D_{m}$ and $H$ are the maximum diameter and the height of the sample after each stage of load.

\section{Experimental Procedure}

The copper was characterized by atomic spectroscopy with a SpectroLAb Junior and observed with metallographic microscope, see Table 1 and Figure 1. The surface roughness of samples and dice are $\mathrm{N} 7^{12}$.

Table 1. Atomic Emission Spectroscopy of the copper samples $(W / W)$

\begin{tabular}{lcccc}
\hline $\mathrm{Zn} \%$ & $\mathrm{~Pb} \%$ & $\mathrm{Sn} \%$ & $\mathrm{P} \%$ & $\mathrm{Ni} \%$ \\
\hline 0.004 & 0.00124 & 0.0043 & 0.0004 & 0.0007 \\
$\mathrm{Te} \%$ & $\mathrm{As} \%$ & $\mathrm{Sb} \%$ & $\mathrm{Cd} \%$ & $\mathrm{Bi} \%$ \\
0.005 & 0.0006 & 0.003 & 0.0007 & 0.0025 \\
$\mathrm{Zr} \%$ & $\mathrm{Au} \%$ & $\mathrm{Cu} \%$ & $\mathrm{Be} \%$ & $\mathrm{Cr} \%$ \\
0.0003 & 0.0019 & 99.9 & 0.0001 & 0.0013 \\
$\mathrm{Si} \%$ & $\mathrm{Mn} \%$ & $\mathrm{~S} \%$ & $\mathrm{Ag} \%$ & $\mathrm{Co} \%$ \\
0.0016 & 0.0056 & 0.0003 & 0.0062 & 0.0016 \\
\hline
\end{tabular}

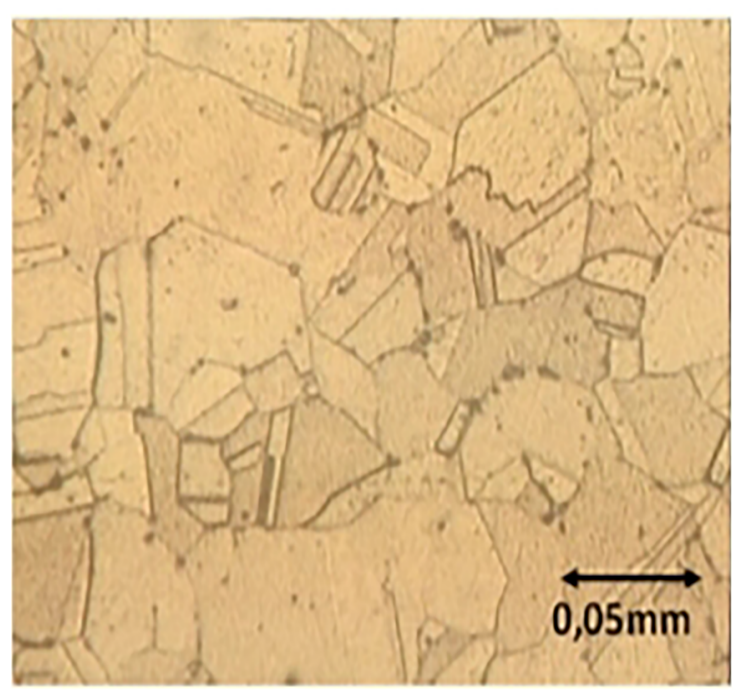

Figure 1. Photomicrography of copper attacked with $\mathrm{H}_{2} \mathrm{O}_{2} / \mathrm{NH}_{4} \mathrm{OH}$

Seventeen compression tests at room temperature were carried out without lubrication with a speed of 0.028 $\mathrm{mm} / \mathrm{s}$. The compression tests were carried out according to ASTM E 9-09A ${ }^{13}$ with the universal testing machine MTS-312.31/227. The samples of cooper were $12.6 \mathrm{~mm}$ of diameter and $20 \mathrm{~mm}$ of height, a slenderness ratio of 1.60 .

The final displacement of the sample was the variable. The first test was made until a displacement of $2 \mathrm{~mm}$, in this way the displacement was increasing, and so on until reach $14 \mathrm{~mm}$ of final displacement at the last test.

The diagrams of Load vs. Displacement are showed in the Figure 2.

The final dimensions of the samples experimentally measured (see figure 3 ) are presented in the Table 2. Figure 4 is a photo of some deformed samples. 


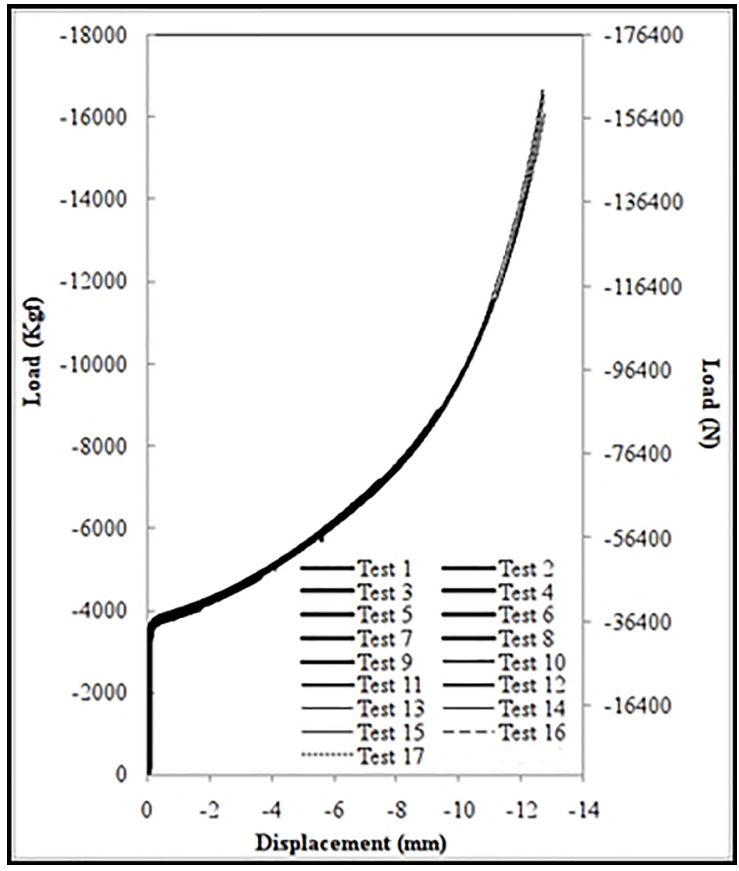

Figure 2. Load vs. Displacement of the seventeen compression tests

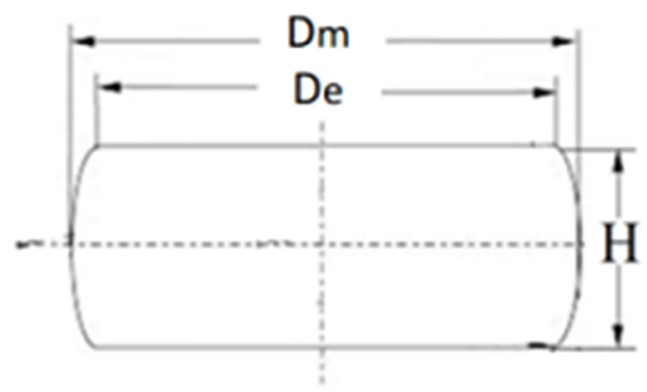

Figure 3. Experimental measurements of the sample: $H$ : height, $D_{m}$ : diameter in the middle, and $\mathrm{D}_{\mathrm{e}}$ : diameter on the bottom

Table 2. Experimental measurements of the samples tested

\begin{tabular}{lcccc}
\hline Test & $\begin{array}{c}\text { Maximum Load } \\
\text { Kgf(N) }\end{array}$ & He (mm) & Dm (mm) & De (mm) \\
\hline 1 & $-0(0)$ & 20.00 & 12.60 & 12.60 \\
2 & $-4075(-39935)$ & 18.46 & 13.50 & 12.96 \\
3 & $-4096(-40141)$ & 18.48 & 13.46 & 13.04 \\
4 & $-4160(-40768)$ & 18.50 & 13.50 & 13.02 \\
5 & $-4829(-47324)$ & 16.58 & 14.52 & 13.44 \\
6 & $-4878(-47804)$ & 16.60 & 14.52 & 13.54 \\
7 & $-5834(-57173)$ & 14.52 & 15.52 & 14.22 \\
8 & $-5878(-57604)$ & 14.58 & 15.50 & 14.22 \\
9 & $-7152(-70090)$ & 12.56 & 16.78 & 15.52 \\
10 & $-8748(-85730)$ & 10.78 & 18.16 & 16.48 \\
11 & $-8771(-85956)$ & 10.68 & 18.06 & 16.58 \\
12 & $-8839(-86622)$ & 10.68 & 18.10 & 16.38 \\
13 & $-11012(-107918)$ & 9.20 & 19.98 & 18.24 \\
14 & $-11194(-109701$ & 8.40 & 19.96 & 18.84 \\
15 & $-16067(-157457)$ & 7.26 & 22.34 & 21.16 \\
16 & $-16549(-162180)$ & 7.36 & 22.35 & 22.56 \\
17 & $-16793(-164571)$ & 7.30 & 22.53 & 21.30 \\
\hline
\end{tabular}

*The lengths are $+/-0.02 \mathrm{~mm}$

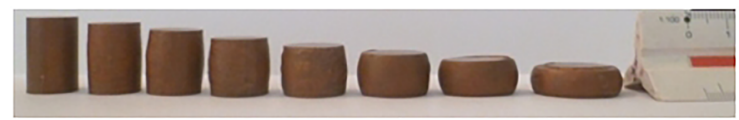

Figure 4. Photo of some deformed samples

Figure 5 is the linear relationship proposed by Joardar et al. ${ }^{10}$ taking the measurements reported by Ebrahimi et $a l .^{8}$ and the final dimensions of the samples measured in this work (Table 2).

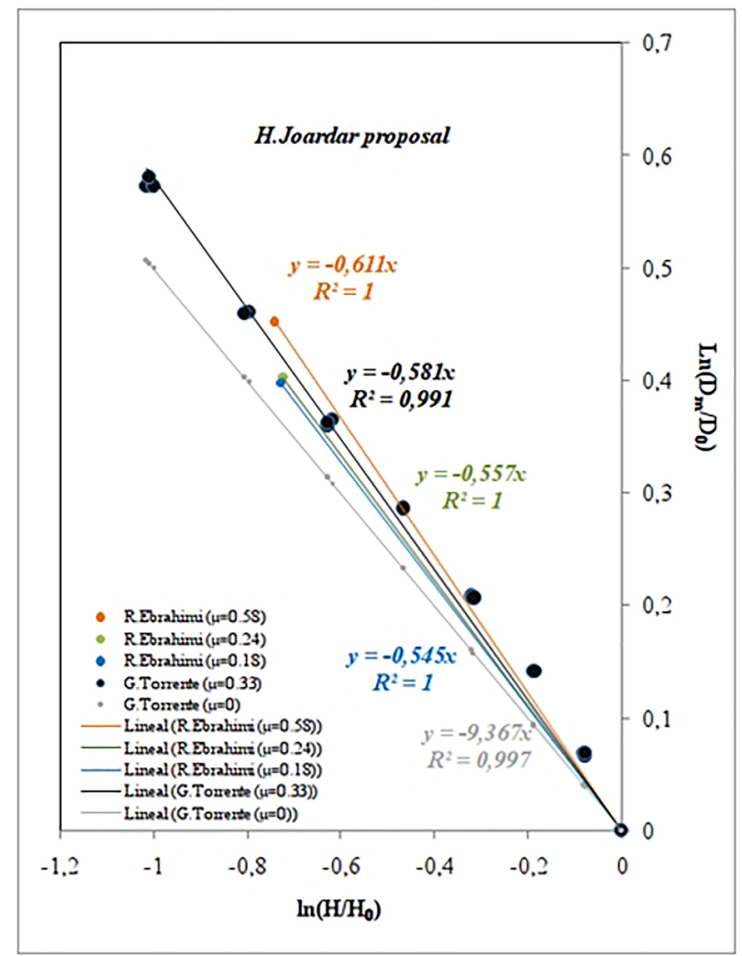

Figure 5. Relationship between logarithm of actual height/initial height and the logarithm of actual maximum diameter/initial diameter

Ebrahimi et al. ${ }^{8}$, Ettouney et al..$^{5}$, Joardar et al..$^{10}$ and Altinbalik et al. ${ }^{11}$ found that the barreling depends mainly on the geometric of the sample and the friction.

A new linear relationship between the maximum diameter $\left(D_{m}\right)$ and the diameter calculated with volume conservation principle $\left(D_{v c p}\right)$ is proposed, see Figure 6.

The empirical relationship for the compression test of copper without lubrication can be written by equation 13 .

$$
\frac{D_{m}-D_{0}}{D_{v c p}-D_{0}}=1.199
$$

Figure 7 shows a comparison between equation 13 and the experimental measurements.

Figure 8 are the slopes $m$ (Figure 6) vs. the friction coefficients $\mu$ reported by Ebrahimi et al. ${ }^{8}$, for the slope $m$ $=1.199$, obtained in this work, the friction coefficient took is 0.36 , sliding friction coefficient between copper and mild steel reported in the references ${ }^{14}$. 


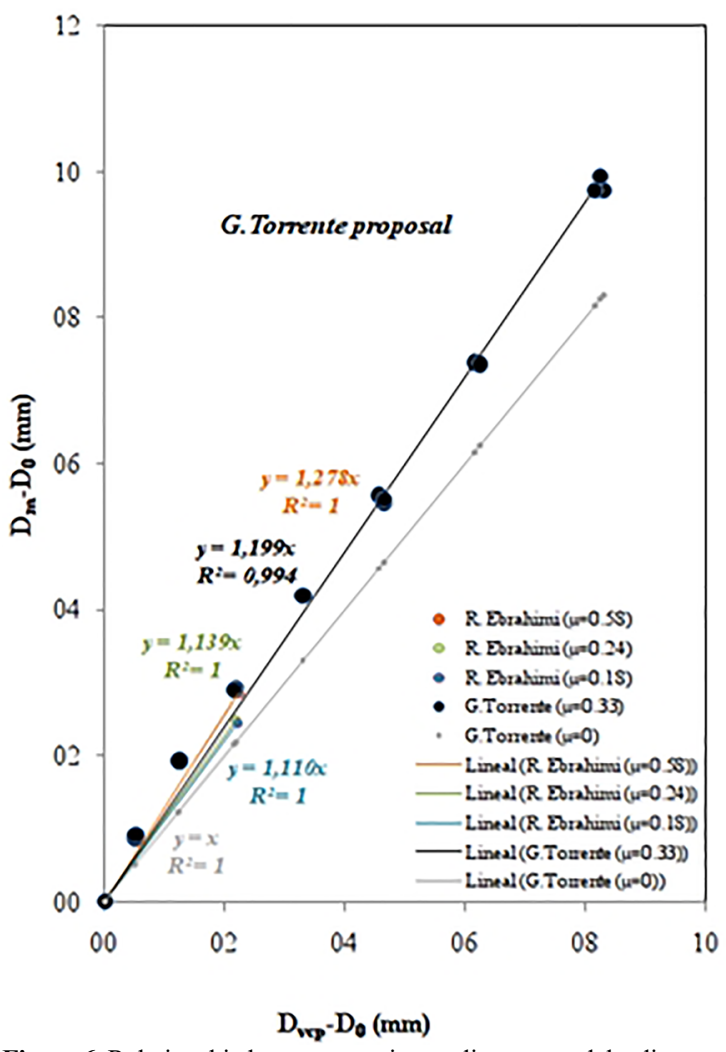

Figure 6. Relationship between maximum diameter and the diameter calculated by volume conservation principle

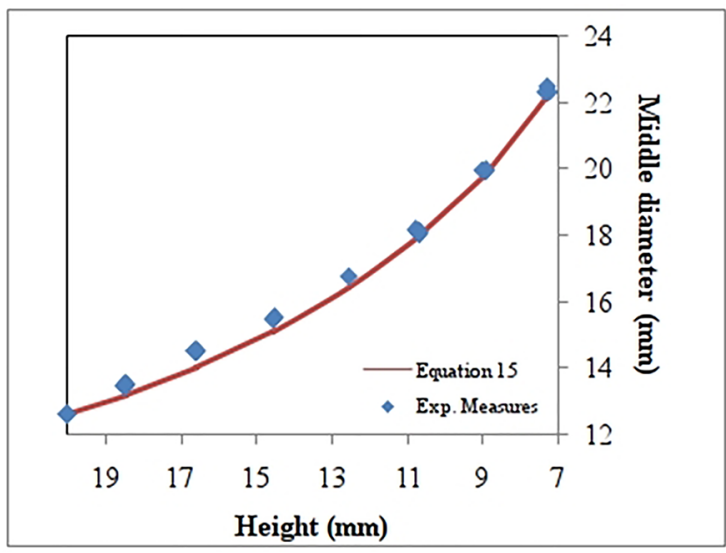

Figure 7. Middle or Maximum diameter measured of experiments and the Middle or Maximum diameter $\left(\mathrm{D}_{\mathrm{m}}\right)$ calculated with the new empirical relationship (Equation 13)

A new empirical relationship (equation 14) is proposed to find the maximum diameter $\left(D_{m}\right)$ of the deformed samples during the compression tests, assuming that the coefficient of friction is constant and the slenderness ratio of the sample is close to 1.6 .

$$
\frac{D_{m}-D_{0}}{D_{v c p}-D_{0}}=e^{0.463 \mu}
$$

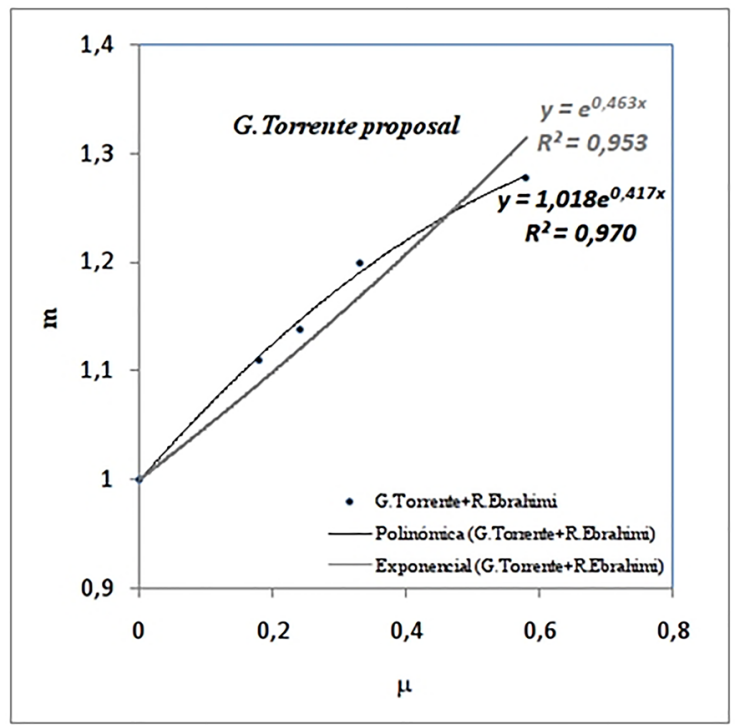

Figure 8. Relationship between the friction coefficient $(\mu)$ and the slope $(m)$

The stress vs. strain curve calculated with this new proposal for friction correction (equations 4,13 and 15) is the black curve in Figure 9.

$$
\varepsilon=2 \ln \left(\frac{D_{m}}{D_{0}}\right)
$$

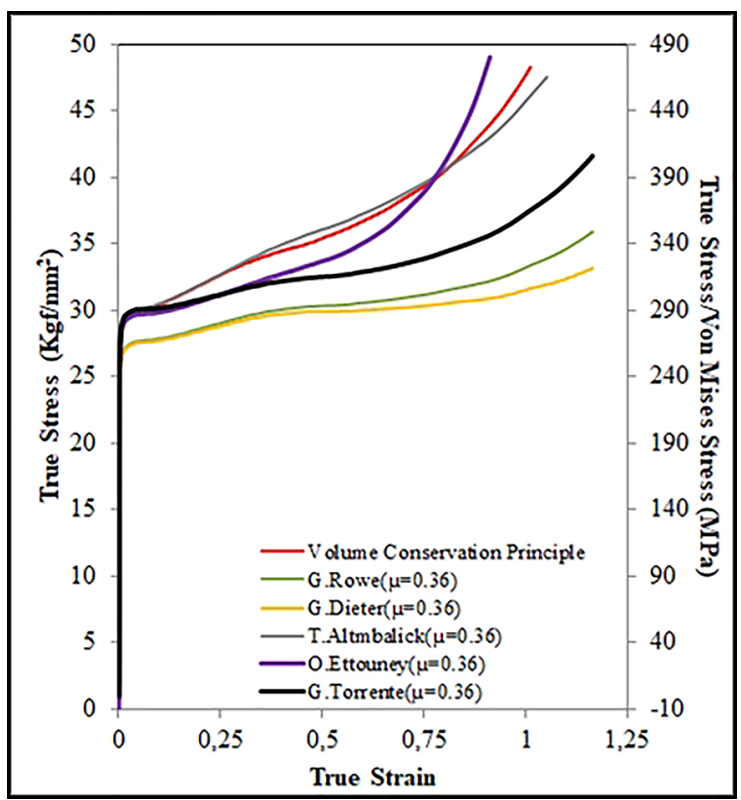

Figure 9. True Stress vs. True Strain of compression test of copper with different friction correction (Volume Conservation Principle, G.Rowe, G.Dieter, T.Altinbalick, O.Ettouney and G.Torrente)

The empirical relationship 13 allows calculate the $D_{m}$ knowing the elongation and the initial dimension of the 
sample without experimental instant measurements of diameters. These instant values of $D_{m}$ allow obtain true stress, taking into account the barreling, for example, with the equations 4 and 15 (black curve in Figure 9), with the friction correction of Ettouney et al. ${ }^{5}$ (purple curve in Figure 9) or with the friction correction of Altinbalik et al. ${ }^{11}$ (gray curve in Figure 9).

Figure 9 is the Stress vs. Strain obtained from equation 13 and with different friction corrections.

A recent work of Wang et al. ${ }^{15}$, using inverse method combined with finite element analysis, shows that the magnitude of barreling increases with increasing friction coefficient.

Yao et al. ${ }^{16}$ and Duran et al. ${ }^{17}$ found a relationship between the barreling, the friction and the slenderness ratio. They said that, possibly, the hardening exponent of the work material has a little effect over the barreling.

This work was made for a slenderness ratio of 1.6 and the effect of hardening exponent is neglected in the equation 14 .

\section{Numerical Analysis}

The numerical analysis was made with finite elements models. The mesh was made in $\mathrm{Gmsh}{ }^{18}$ with a size element factor of 1.75. The finite element simulations were made in Calculix ${ }^{19}$. The mesh size element factor was checked.

The dies were simulated like rigid.

The copper was simulated like an isotropic elastic material until yield stress; and then it was simulated like an incremental plasticity material with hardening..$^{20}$

The elastic behavior of copper was simulated with a Young modulus $E=11000 \mathrm{Kgf} / \mathrm{mm}^{2}(107800 \mathrm{MPa}){ }^{21,22}$ and a Poisson ratio of $v=0.33^{23}$. See equations 16 and 17 , where $\varepsilon$ is the strain. These values were determined from references and experimental measurements, see Figure 9.

$$
\begin{gathered}
\sigma=E \varepsilon \\
v=-\frac{d \varepsilon_{X}}{d \varepsilon_{Z}}
\end{gathered}
$$

The behavior of incremental plasticity material with hardening was calculated with the tests. The Stress vs. Strain was calculated from the experimental measurements of load and displacement (Figure 2), the maximum diameters were calculated with the new empirical relationship (equation 13) to avoid errors by friction coefficient estimation, and the stress and the strain were calculated with equations 4 and 15 (black curve in Figure 9).

The numerical analysis is static with SGI Solver and supposes a symmetrical behavior of the sample; therefore the control volume is the half of the sample. See Figure 10.

The simulation has boundary conditions in three surfaces (see Figure 10):

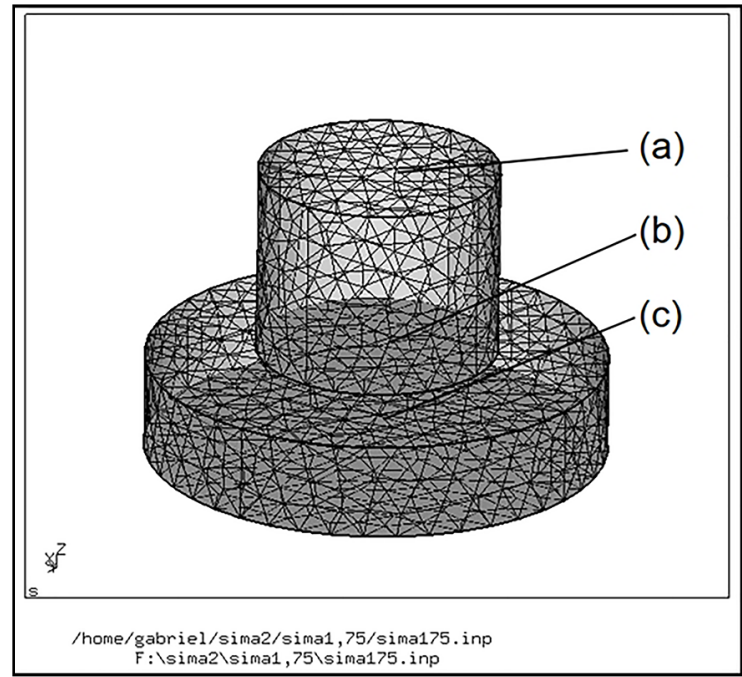

Figure 10. Control volume, surface element edges and boundary conditions: (a) The surface in middle of the copper sample, (b) The surface on the bottom of the copper sample, (c) the top surface of the bottom dice

a) The surface in middle of the copper sample. This surface is free to move and on it a compression load is applied. The compression load goes from 0 to $-16000 \mathrm{Kgf}$ (159906 $\mathrm{N})$. Another condition on this surface is the multiple point constraint of the type plane (MPC-PLANE).$^{19}$ This second condition avoids fake flash on this surface. ${ }^{24}$

b) The surface on the bottom of the copper sample. This surface is free to move and complete the contact pair with the bottom die, mortar contact with coulomb friction.

c) The top surface of the bottom dice. This surface has not freedom degrees and it was defined to complete the contact pair with the copper sample.

Figure 11 is a comparison between the sample dimensions obtained with the simulation and the experimentally measured.

Figure 11 shows that the friction coefficient has a strong effect over the diameter on the bottom and a minor effect over the height and the middle diameter of the sample.

Figure 11 shows that the sample dimensions obtained from the simulation with a friction coefficient of 0.36 are the same as experimental measurements, but for bigger strains, the sample dimensions obtained with friction coefficients of 0.20 or 0.10 are nearest to the experimental measurements, with differences less than $4.21 \%$.

The aim of this works is propose an empirical equation to find instant maximum diameters during the compression test. The empirical relationship 14 supposes friction coefficient constant, but the numerical simulations (Figure 11) show that, possibly, the friction coefficient decreases meanwhile the sample is hardening.

Numerical simulation shows that, possibly, the hardening of the sample has a little effect on the friction coefficient, and therefore on the barreling, such as was observed by Yao et al. ${ }^{16}$ and Duran et al. ${ }^{17}$ 


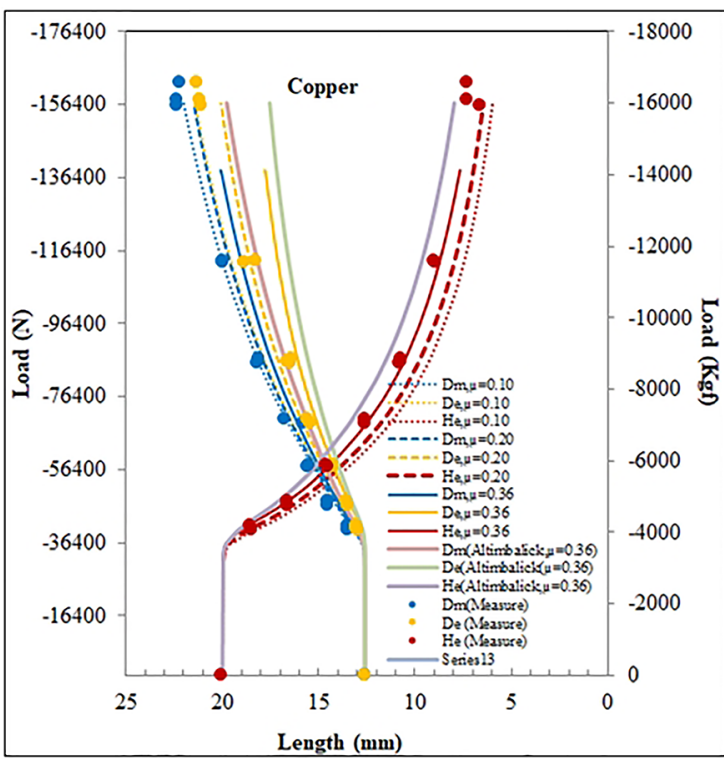

Figure 11. Simulation results for a compression test of copper and main lengths measured on the deformed samples

Figure 11 shows that the simulation made with this new proposal is nearer to the experimental tests than the simulation made with the corrections of Dieter and Rowe. ${ }^{24}$

Figures 12 and 13 are cuts of the samples and show the Von Mises equivalent strain and Von Mises Stress for a load of $-8740 \mathrm{Kgf}(-85590 \mathrm{~N})$. and with a friction coefficient of $\mu=0.36$.

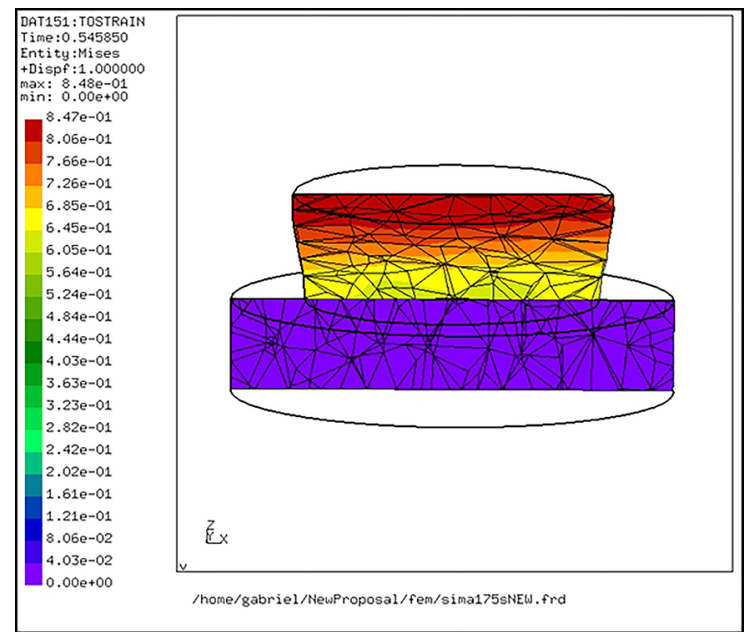

Figure 12. Simulation results, Von Mises Equivalent Strain for a friction coefficient 0.36 and a load of $-8740 \mathrm{Kgf}(-85590 \mathrm{~N})$

Figure 12 shows the friction effect over the strain in the sample. The strain has a minimum on the bottom and a maximum in the middle. This behavior was described by Dieter. ${ }^{25} \mathrm{He}$ described three zones of deformation: Dead metal zone on the bottom, Intense Shearing in the middle and Moderate Deformation on the edges in the middle.

Figure 13 is Von Mises stress in the sample. This figure shows a Von Mises stress between 31.9 and $32.9 \mathrm{Kgf} / \mathrm{mm}^{2}$
(306-322 MPa), stress values for a strain of 0.67 (Figure 9), strain observed in the middle of the sample, near the zones known as Intense Shear and Moderate Deformation (Figure 12).

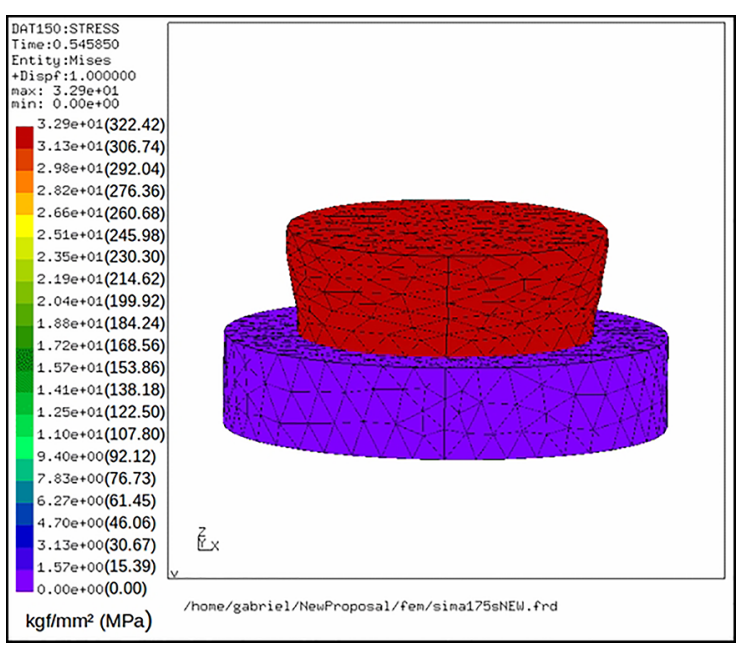

Figure 13. Simulation results, Von Mises Stress $\left(\mathrm{Kgf} / \mathrm{mm}^{2}\right.$ or MPa) for a friction coefficient of 0.36 and a load of $-8740 \mathrm{Kgf}(-85590 \mathrm{~N})$

\section{Conclusions}

The friction corrections proposed by Rowe et al., Dieter et al., Ebrahimi et al., Ettouney et al., Joardar et al. and Altinbalik et al. are functions of the sample dimension and friction coefficients. This work proposes a new friction correction that also depended of the dimension of the sample and the friction coefficient.

The proposal is a new empirical relationship to obtain the instantaneous maximum diameters of the sample directly from compression tests data and initial dimensions of sample.

The friction correction proposed in this work takes into account the barreling of sample during the compression test. This new proposal gives mechanical behavior similar to those obtained by the friction correction of Dieter and Rowe.

The simulation made with this new proposal for friction correction give results very closed to the experiments, with differences minor to $4.21 \%$.

Numerical simulations show that, possibly, the friction coefficient change with the hardening of the sample.

The numerical simulation shows a greater strain in the middle than on the bottom.

\section{Acknowledgments}

Thanks to Professors Mary Torres, Orlando Pelliccione, and Gabriela Martinez, all of them from the Mechanical Department. Thanks to E-Laboratory and Mr. Henry Lopez. Thanks to Dean of Research and Development (DID) of Simon Bolivar University-Venezuela for support. 


\section{References}

1. Kalpakjian S, Schimd S. Manufactura, Ingeniería y Tecnología. 5a ed. Mexico: Pearson; 2008

2. Li Y, Akihiko C. Aplication of Smart Hot Forging Technique in Producing Biomedical Co-Cr-Mo Artificial Implants. In: Niinomi M, Narushima T, Nakai, M, eds. Advances in Metallic Biomaterials: Processing and Applications. Berlin, Heidelberg: Springer; 2015. p. 57-83. DOI: 10.1007/978-3-662-46842-5.

3. Rowe G. An Introduction to the Principles of Metalworking. London: Edward Arnold; 1965.

4. Dieter GE. Mechanical Metallurgy. $3^{\text {rd }}$ ed. New York: McGrawHill; 1986.

5. Ettouney O, Hardt DE. A Method for In-Process Failure Prediction in Cold Upset Forging. Journal of Engineering for Industry. 1983;105(3):161-167.

6. Bridgman PW. Studies in Large Plastic Flow and Fracture. New York: McGraw-Hill; 1952.

7. Kulkarni KM, Kalpakjian S. A study of Barreling as an Example of Free Deformation in Plastic Working. Journal of Engineering for Industry. 1968;91(3):743-754. DOI: 10.1115/1.3591680

8. Ebrahimi R, Najafizadeh A. A new method for evaluation of friction in bulk metal forming. Journal of Materials Processing Technology. 2004;152(2):136-143. DOI: 10.1016/j. jmatprotec.2004.03.029

9. Li YP, Onodera E, Matsumoto H, Chiba A. Correcting the Stress-Strain Curve in Hot Compression Process to High Strain Level. Metallurgical and Materials Transactions A. 2009;40(4):982-990. DOI: 10.1007/s11661-009-9783-7

10. Joardar H, Das N, Sutradhar G, Singh S. Barreling of solid composite (LM6/SiCp) cylinders under uniaxial compressive load. International Journal of Applied Sciences and Engineering Research. 2013;2(4):435-445. DOI: 10.6088/ijaser.020400006

11. Altinbalik T, Çan Y. An upper bound analysis and determination of the barrelling profile in upsetting. Indian Journal of Engineering \& Materials Sciences. 2011;18(6):416-424.

12. International Organization for Standardization (ISO). ISO 468:1982 - Surface roughness -- Parameters, their values and general rules for specifying requirements. Geneva: ISO; 1982.
13. ASTM International. ASTM E 9-09A - Standard Test Method for the Compression Testing of Metallic Materials at Room Temperature. West Conshohocken: ASTM International; 2009

14. Davis JR, eds. Concise Metals Engineering Data Book. Materials Park: ASM International; 1997.

15. Wang X, Li H, Chandrashekhara K, Rummel SA, Lekakh S, Van Ecken DC, et al. Inverse finite element modeling of the barreling effect on experimental stress-strain curve for high temperature steel compression test. Journal of Materials Processing Technology. 2017;243:465-473. DOI: 10.1016/j.jmatprotec.2017.01.012

16. Yao Z, Mei D, Shen H, Chen Z. A Friction Evaluation Method Based on Barrel Compression Test. Tribology Letters. 2013;51(3):525-535. DOI 10.1007/s11249-013-0164-4

17. Duran D, Karadogan C. Determination of Coulomb's Friction Coefficient Directly from Cylinder Compression Tests. Strojniski Vestnik. 2016;62(4):243-251. DOI: 10.5545/ sv-jme.2015.3141

18. Geuzaine C, Remacle JF. Gmsh: a three-dimensional finite element mesh generator with built-in pre- and post-processing facilities. International Journal for Numerical Methods in Engineering. 2009;79(11):1309-1331.

19. Dhondt G. CalculiX CrunchiX USER'S MANUAL version 2.7. Available from: <http://web.mit.edu/calculix v2.7/CalculiX/ ccx_2.7/doc/ccx/index.html >. Access in: 25/04/2018.

20. Dunne F, Petrinic N. Introduction to Computational Plasticity. Oxford: Oxford University Press; 2005.

21. Gordon J. Estructuras o Porque Las Cosas No Se Caen. Madrid: Calamar Ediciones; 2004.

22. Ortiz Berrocal L. Elasticidad. Madrid: McGraw-Hill; 1998.

23. Schackelford JF. Introdución a la Ciencia de Materiales para Ingenieros. Madrid: Pearson; 1995.

24. Torrente-Prato JG. Numerical and experimental studies of compression-tested copper, mortar contact method. Dyna. 2017;84(202):255-262. DOI: 10.15446/dyna.v84n202.61832

25. Dieter GE, Kuhn HA, Semiatin SL. Handbook of Workability and Process Design. Materials Park: ASM International; 2003. 